\title{
A indústria cerâmica vermelha de Campos dos Goitacazes e a inclusão social das artesãs da baixada campista através do projeto Caminhos de Barro
}

\author{
(The red ceramic industry in Campos dos Goitacazes \\ and the social inclusion of artisans from Baixada Campista \\ through the Caminhos de Barro project)
}

\author{
I. S. Ramos, J. Alexandre, M. G. Alves, V. Vogel, M. Gantos \\ Laboratório de Engenharia Civil - LECIV, Centro de Ciências e Tecnologia - CCT \\ Universidade Estadual do Norte Fluminense - UENF \\ Av. Alberto Lamego 2000, Parque Califórnia, Campos dos Goytacazes, RJ 28013-600 \\ tel.: OXX-22-2726-1515 \\ izabelram@gmail.com,jonas@uenf.br
}

\begin{abstract}
Resumo
O Parque industrial de Campos dos Goytacazes é formado por mais de cem cerâmicas, absorvendo, segundo informações do próprio segmento, cerca de 5000 funcionários. Este tipo de trabalho, de um modo geral, emprega pessoas capazes de suportar serviços pesados, excluindo desta forma mulheres, idosos e portadores de deficiência. O Projeto Caminhos de Barro, implantado pela Universidade Estadual do Norte Fluminense Darcy Ribeiro (UENF), no ano de 2000, tem como finalidade capacitar, na arte cerâmica artesanal, essas comunidades excluídas do processo industrial de produção de tijolos e telhas. O presente trabalho tem como primícia contribuir para uma melhora na tecnologia adotada, pela primeira geração de artesãs formada na Oficina Caminhos de Barro, adequando a matéria prima utilizada à nova atividade através de mapeamento, classificação e caracterização dos materiais da região na forma in natura, ocupando-se, igualmente do seu comportamento após a queima. A mesma análise técnica utilizada para caracterização e adequação dos produtos industrializados pelas industrias cerâmicas mostrou-se também adequada para o artesanato. A matéria prima estudada, em principio, apresentou as qualidades necessárias ao trabalho artesanal como pode ser observado pelos produtos obtidos levando a um menor grau de perda. Porém a criação de um padrão mais adequado de matéria prima a ser utilizado na arte cerâmica da baixada campista demandará, portanto, mais tempo, recursos e estudo, pois as propriedades desejadas de cada artefato tais como: cor, permeabilidade e acabamento podem estar associados a pequenas variações físicas e mineralógicas.
\end{abstract}

Palavras-chave: artesanato, Baixada Campista, argila.

\begin{abstract}
The industrial park of the Campos dos Goytacazes is formed for more than one hundred ceramics, absorbing, by mean information of the proper segment, about 5000 employees. This type of work in a general way uses capable person to support heavy services excluding: women, deficient and old person. The Project Caminhos de Barro implanted for the State University of Norte Fluminense Darcy Ribeiro (UENF), in 2000, has as purpose to enable, in the ceramic art, these excluded communities of the ceramic industrial process. The present work has as objective to contribute for an improvement in the adopted technology, for the first generation of artisans formed in the Workshop Caminhos de Barro, adjusting the raw material used to the new activity through mapping, classification and characterization the materials of region in nature and its behavior after the burning. The same analysis technique used for characterization and adequacy of the products industrialized for the ceramic industries also revealed adequate for the workmanship. The raw material studied, in the begin, presented the necessary qualities to the artisan work as it can be observed by the gotten products leading to a lesser loss. However the creation of a standard more adjusted of raw material to be used in the ceramic art of the Baixada Campista will demand, therefore, more time, resources and study, therefore the desired properties of each device such as: color, permeability and finishing can be associates the small physical and mineralogical variations.
\end{abstract}

Keywords: workmanship, clay.

\section{INTRODUÇÃO}

O Município de Campos dos Goytacazes, no Estado do Rio de Janeiro, tem no pólo cerâmico uma de suas mais importantes atividades econômicas. Este pólo congrega, hoje, mais de cem empresas produtoras, as quais geram, mensalmente, cerca de noventa milhões peças, entre telhas, tijolos e lajotas, respondendo por aproximadamente três mil 
empregos diretos. Porém uma parcela da população visa também, a possibilidade de geração de renda na própria região de São Sebastião, utilizando matéria prima local, uma vez que as famílias ali instaladas vivem através de empregos das Cerâmicas da região. Uma das possibilidades passíveis a vir acrescentar rendimento aos grupos familiares locais seria $\mathrm{o}$ artesanato.

Com vistas ao aprimoramento dos processos que envolvem o setor cerâmico da região, a Universidade Estadual do Norte Fluminense Darcy Ribeiro - UENF, em conjunto com a Secretaria de Ciência, Tecnologia e Inovação - SECTI, formulou e iniciou, em 2000, o Programa Estudos para o Desenvolvimento Sustentado do Pólo Cerâmico de Campos dos Goytacazes. Entre as ações propostas, figurava o investimento numa alternativa de geração de renda e inclusão, na cadeia produtiva, dos familiares dos trabalhadores da indústria cerâmica da Baixada Campista. Essa escolha foi motivada pela precariedade das condições de vida a que estão sujeitas às famílias dos oleiros e pela inexistência de oportunidades para

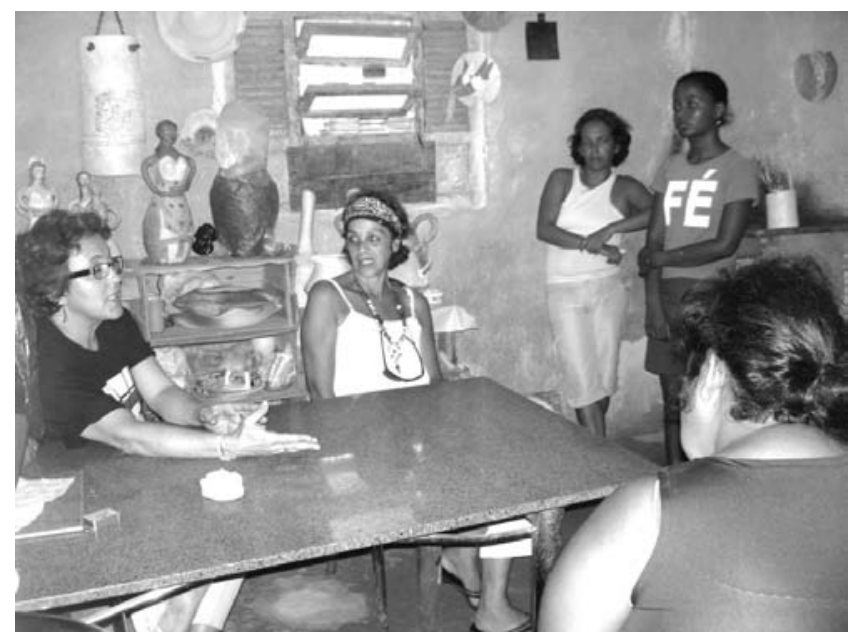

Figura 1: Reunião com as artesãs em São Sebastião.

[Figure 1: Meeting with the artisans in São Sebastião.]

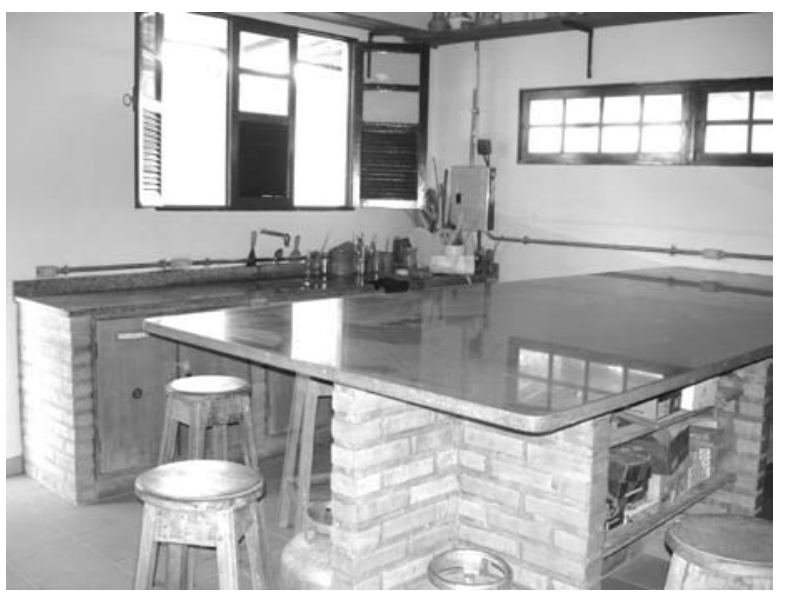

Figura 2: Oficina Caminhos de Barro implantada em uma escola no mesmo lugarejo.

[Figure 2: Workshop Caminhos de Barro implanted at a school in the same village.] mulheres e jovens, contingente significativo não absorvido pela cadeia produtiva, ou a ela incorporado de maneira precária. Assim nasceu o Projeto Arte, Educação e Cidadania: Oficina de Arte Cerâmica Caminhos de Barro como uma estratégia de desenvolvimento humano local, cuja expectativa é criar um espaço alternativo para a formação: artística, cultural e técnica das comunidades desfavorecidas da Baixada Campista, locus privilegiado de produção artesanal e industrial de telhas e tijolos (Figs. 1 e 2).

\section{JUSTIFICATIVA}

Aarte cerâmica desenvolvida em diversas regiões brasileiras baseia-se em formulações empíricas e regionais. Isso, de certa forma, prejudica sua disseminação, pois as matérias-primas utilizadas são extremamente complexas e, quase sempre aplicadas na sua forma bruta; isto é, não existe uma preocupação inicial em incorporar a qualidade da matéria-prima como componente indissociável dos artefatos, como também não existe a adoção de mecanismos de registro sistemático do saber adquirido, de modo a garantir a apropriação e a continuidade do processo para além do local em que é produzido. Esta se tem mantido, através de um aprendizado que se transmite de geração para geração, na prática cotidiana.

Em Campos, tal mecanismo não se constituiu ainda, uma vez que aqui se está "inventando uma tradição artesanal". $\mathrm{O}$ trabalho proposto articula as competências do Centro de Ciências do Homem (CCH) e do Centro de Ciências Tecnologias (CCT) da UENF visando implementar um enfoque cientifico e tecnológico no processo de criação de uma tradição de arte cerâmica no município de Campos dos Goytacazes que também possa servir como referência para o setor. Visto que a primeira geração de artesãs, formada pelo Projeto nestes cinco anos de existência, mesmo com todo o sucesso alcançado, nas inúmeras participações do grupo em exposições e eventos, têm enfrentado dificuldades técnicas consideráveis para o aprimoramento do seu trabalho. Essas dificuldades são originadas da utilização de uma matériaprima originariamente destinada a outro tipo de atividade - a fabricação de telhas e tijolos. A argila e a queima feita nos fornos das cerâmicas existentes, ambas igualmente inadequadas à arte cerâmica, são responsáveis hoje por uma perda de cerca de $30 \%$ da produção do grupo.

\section{OBJETIVOS}

Objetivo geral: Apoiar o desenvolvimento de uma cerâmica artesanal aproveitando conhecimentos metodológicos científicos, já desenvolvidos pela Universidade Estadual do Norte Fluminense no âmbito da cerâmica vermelha.

Objetivos específicos: Caracterizar a matéria-prima, existentes nas proximidades das residências das artesãs do Projeto Caminho de Barro, maximizando os seus modos de utilização para confeção de peças artesanais.

- Acompanhar a produção de artefatos cerâmicos produzidos com a matéria prima coletada e analisada, observando os resultados obtidos. 


\section{ÁREA DE ESTUDO}

A Cidade de Campos dos Goytacazes está localizada na região norte do Estado do Rio de Janeiro, aproximadamente a $279 \mathrm{~km}$ da capital estadual (Fig. 3), Rio de Janeiro, com uma área de $4.037 \mathrm{~km}^{2}$, sendo o maior município do Estado e possuindo uma população de 429.667 habitantes [1].

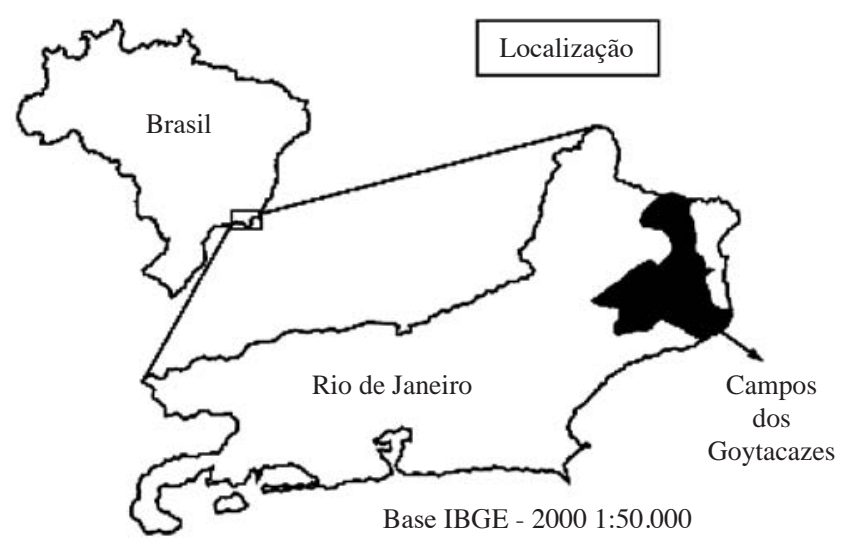

O Município apresenta uma grande reserva de argilas originárias de processo de decantação de materiais siltoargilosos da carga de suspensão em ambientes de planície de inundação após eventos de enchentes do Rio Paraíba do Sul [2]; a área de concentração destes depósitos encontrase à margem direita do Rio Paraíba do Sul, ao longo da estrada RJ-216 que liga a cidade de Campos ao Farol de São Tomé.

\section{METODOLOGIA}

A metodologia adotada compreendeu várias etapas:

\section{Identificação e mapeamento através de GPS}

Primeiramente os pontos, nos quais foram retiradas amostras, foram localizados por meio de GPS e plotados em imagem de satélite previamente georeferenciada.

Caracterização dos materiais por meio de análises físicas e químicas

Análise granulométrica: foram feitos ensaios para determinar as distribuições granulométricas das massas utilizadas, via úmida por peneiramento e sedimentação conforme a NBR 7181 [3] no Laboratório de Mecânica dos Solos do LECIV/CCT/UENF.

Massa específica real dos grãos: as amostras foram secas a $110^{\circ} \mathrm{C}$ até a massa constante. $\mathrm{O}$ ensaio foi realizado segundo a NBR-6471 [4].

Limites de Atterberg: Plasticidade e liquidez: foram realizados estes ensaios segundo a norma ABNT, NBR-7180 [5] e NBR-6459 [6].

Análise química quantitativa: foi realizada segundo metodologia estabelecida no LECIV/CCT/UENF, por meio de análises por energia dispersiva de raios $\mathrm{X}$ (EDX).

Confecção de corpos de prova, retração linear e cor na queima

As três amostras coletadas na área fonte foram passadas na peneira $\mathrm{n}^{\circ} 20(0,85 \mathrm{~mm})$ e secas após $24 \mathrm{~h}$ em estufa a $110^{\circ} \mathrm{C}$ e umedecidas [7], com 7\% de umidade até homogeneização. Após isso, as amostras foram levadas a uma prensa manual e comprimidas com $200 \mathrm{Kgf} / \mathrm{cm}^{2}$. Os corpos de prova foram moldados na forma de pastilhas com diâmetro $3 \mathrm{~cm}$. Os processos de secagem e queima dos corpos de prova foi realizado a $110{ }^{\circ} \mathrm{C}$ (estufa) e $750{ }^{\circ} \mathrm{C}$, respectivamente, em forno mufla eletrônico, com taxa de aquecimento $5{ }^{\circ} \mathrm{C} / \mathrm{min}$., com patamar de queima de $3 \mathrm{~h}$. O resfriamento ocorreu naturalmente durante a noite até temperatura ambiente. Após a queima na temperatura de $750{ }^{\circ} \mathrm{C}$, as amostras foram medidas para a verificação da retração linear e observação da cor de cada pastilha.

Confecção e queima de objetos produzidos com o material analisado

As artesãs utilizam a matéria prima tal como a recolhem nas jazidas, fabricando suas peças usando as técnicas básicas do processo de modelagem. Estas obedecem a uma seqüência que se inicia com a preparação da matéria prima cujo procedimento consiste em bater e sovar bastante o material para torná-lo mais homogêneo, maleável e eliminar pedras ou outros materiais orgânicos. Em seguida, passam à modelagem das peças utilizando as técnicas de rolete ou cobra que consiste, na fabricação de rolos que vão sendo "colados" uns sobre os outros utilizando-se de uma mistura de argila, água e vinagre chamada barbotina, até a conformação da peça no tamanho desejado. Após a modelagem são feitos o acabamento e a decoração. As peças são postas a secar, protegidas do sol e do vento e às vezes, cobertas com um saco plástico, para um maior controle do processo. Depois da secagem são levadas ao forno para a queima. Inicialmente as queimas eram feitas integralmente nos fornos das olarias. Com a evolução do trabalho, algumas artesãs hoje já possuem fornos rústicos, em suas residências, onde queimam grande parte de sua produção, reservando às olarias as peças de maiores dimensões. Durante a confecção dos artefatos foram realizados registros fotográficos por meio de uma câmara digital.

\section{RESULTADOS E DISCUSSÃO}

Segue abaixo a Carta Imagem (Fig. 4) com a identificação da área fonte de material (Saquarema) e as localidades nas quais se encontram as oficinas das artesãs: Poço Gordo e São Sebastião.

\section{Caracterização do material}

Análise granulométrica: A Tabela I apresenta os 


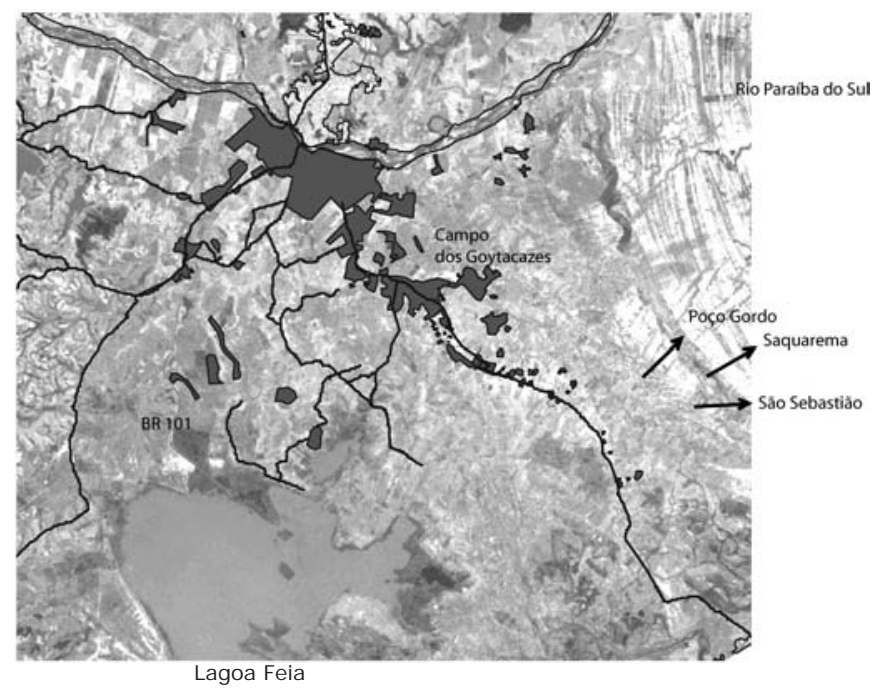

Figura 4: Carta Imagem com as localidades e área fonte plotadas. [Figure 4: Image with the localities and clay deposit.]

resultados obtidos com os ensaios realizados, via úmido por peneiramento e sedimentação.

São apresentadas a seguir as faixas granulométricas das amostras analisadas:

- Fração A: A variação do teor de argila das camadas ficou entre $45 \%$ e $62 \%$;

- Fração silte: A quantidade de fração silte ficou entre $29 \%$ e $50 \%$;

- Fração areia fina: A faixa de variação foi de 4\% a 7\%.

Analisando as frações granulométricas do material coletado na jazida observa-se uma predominância de material fino, não havendo nenhuma porcentagem de areia média a grossa, indicando um material apropriado à execução de artefatos cerâmicos.

Limites de Atterberg: Limites de Plasticidade e Liquidez: os resultados representam uma média de cinco determinações e estão apresentados a seguir na Tabela II.

Apesar das porcentagens das frações argila e silte dos pontos serem similares, os resultados dos índices de plasticidade apresentaram valores diversificados, sendo que a amostra S2 foi a que apresentou o valor mais baixo. Isto pode ser devido à porcentagem de areia fina que ocorreu neste ponto. O que não interferiu na elaboração dos artefatos cerâmicos.

Observa-se que as amostras apresentadas na Tabela III encontram-se dentro da faixa de valores para a massa específica real dos grãos das argilas da região do Município
Tabela I - Granulometria das amostras.

[Table I - Granulometry of the samples.]

\begin{tabular}{ccccccc}
\hline \multicolumn{6}{c}{ GRANULOMETRIA } \\
\hline Camadas & $\begin{array}{c}\text { Argila } \\
(\%)\end{array}$ & $\begin{array}{c}\text { Silte } \\
(\%)\end{array}$ & \multicolumn{4}{c}{ Areia (\%) } \\
\cline { 5 - 7 } & Fina & Média & Grossa & $\begin{array}{c}\text { Pedregulhos } \\
(\%)\end{array}$ \\
\hline S1 & 63 & 31 & 6 & - & - & - \\
S2 & 54 & 39 & 7 & - & - & - \\
S3 & 45 & 50 & 5 & - & - & - \\
\hline
\end{tabular}

Tabela II - Limites de Atterberg.

[Table II - Atterberg limits.]

\begin{tabular}{cccc}
\hline Material & $\begin{array}{c}\text { LL (Limite de } \\
\text { Liquidez) }\end{array}$ & $\begin{array}{c}\text { LP(Limite de } \\
\text { Plasticidade) }\end{array}$ & $\begin{array}{c}\text { IP (Índice de } \\
\text { Plasticidade) }\end{array}$ \\
\hline S 1 & 62 & 31 & 31 \\
S 2 & 51 & 28 & 23 \\
S 3 & 60 & 30 & 30 \\
\hline
\end{tabular}

de Campos dos Goytacazes-RJ estudada por Alexandre [8] o que denota uma composição química similar as normalmente utilizadas pelas indústrias cerâmicas mostrando dessa forma uma certa homogeneidade da matéria prima regional.

Tabela III - Massa especifica real dos grãos.

[Table III - True specific mass of the grains.]

\begin{tabular}{cc}
\hline Material & massa específica real dos grãos $\left(\mathrm{g} / \mathrm{cm}^{3}\right)$ \\
\hline$S$ S & 2,72 \\
2 & 2,69 \\
S 3 & 2,71 \\
\hline
\end{tabular}

\section{Análise Química Quantitativa}

Pode notar que os teores de $\mathrm{SiO}_{2}$ e de $\mathrm{Al}_{2} \mathrm{O}_{3}$ das amostras são similares, havendo uma maior variação nos outros elementos listados. Em termos de cerâmica artesanal um dos óxidos que se deve observar, com a devida cautela, é o óxido de ferro, que é um dos responsáveis pela coloração avermelhada das peças quando queimadas, quanto mais ferro mais avermelhado será o produto final. Isto foi verificado na amostra S3 que apresentou uma cor bem diferenciada das outras.

\section{Retração linear e cor na queima}

Após a queima a $750{ }^{\circ} \mathrm{C}$ os corpos de prova foram

Tabela IV - Componentes químicos das massas argilosas. [Table IV - Chemical components of the raw material.]

\begin{tabular}{ccccccccccccc}
\hline Amostras & $\mathrm{SiO}_{2}$ & $\mathrm{Al}_{2} \mathrm{O}_{3}$ & $\mathrm{Fe}_{2} \mathrm{O}_{3}$ & $\mathrm{CaO}$ & $\mathrm{K}_{2} \mathrm{O}$ & $\mathrm{TiO}_{2}$ & $\mathrm{~V}_{2} \mathrm{O}_{5}$ & $\mathrm{ZrO}_{2}$ & $\mathrm{SO}_{3}$ & $\mathrm{MnO}$ & $\mathrm{CuO}$ & $\mathrm{SrO}$ \\
\hline $\mathrm{S} 2$ & 42,17 & 55,14 & 1,89 & 0,06 & 0,30 & 0,41 & 0,01 & 0,05 & - & - & & \\
$\mathrm{S} 3$ & 44,32 & 38,47 & 10,52 & 0,40 & 2,43 & 1,73 & 0,13 & 0,03 & 1,84 & 0,01 & 0,04 & 0,01 \\
\hline
\end{tabular}


medidos para a verificação da retração linear. Nota-se na Tabela V que os valores de retração entre as amostras 1 e 2 são muito próximos, sendo que a amostra S3 apresentou uma retração maior. Este resultado pode está relacionado com a fração argila e areia de cada amostra, ou seja, quanto maior o teor de argila, provavelmente maior a retração linear, porém como as amostras S1 e S2 apresentaram um teor de areia mais alto do que a S3, isto acabou interferindo na retração dos corpos de prova.

Quanto à cor na queima, os resultados mostraram diferenças de cores nos materiais analisados, proveniente da variação dos teores de óxidos, existindo uma diferença sensível na amostra 3 em relação às demais.

Tabela V - Retração linear das amostras a $750{ }^{\circ} \mathrm{C}$.

[Table $\mathrm{V}$ - Linear retraction of the samples at $750^{\circ} \mathrm{C}$.]

\begin{tabular}{cc}
\hline Material & Retração Linear (\%) \\
\hline S 1 & 4,24 \\
S 2 & 4,54 \\
S 3 & 6,14 \\
\hline
\end{tabular}

\section{RESULTADOS DA CONFECÇÃO E QUEIMA DE OBJETOS PRODUZIDOS}

Os problemas antes detectados com o uso de material proveniente das olarias, foram significativamente reduzido com o uso da matéria prima in natura (Fig. 5) previamente caracterizada.

O material utilizado apresentou boa plasticidade, contendo uma baixa porcentagem de areia, dando um acabamento refinado as peças cerâmicas (Figs. 6 e 7). Isto não seria possível se a fração areia fosse grossa o que faria com que as peças apresentassem pequenas ondulações,

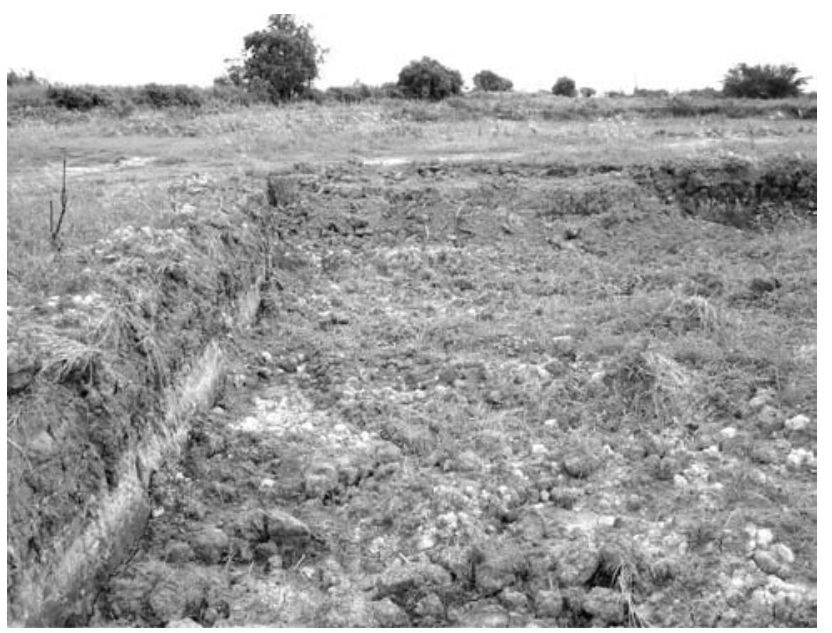

Figura 5: Cava de Argila na região de Saquarema onde se coletou o material.

[Figure 5: Mine in Saquarema, where the material is collected.]
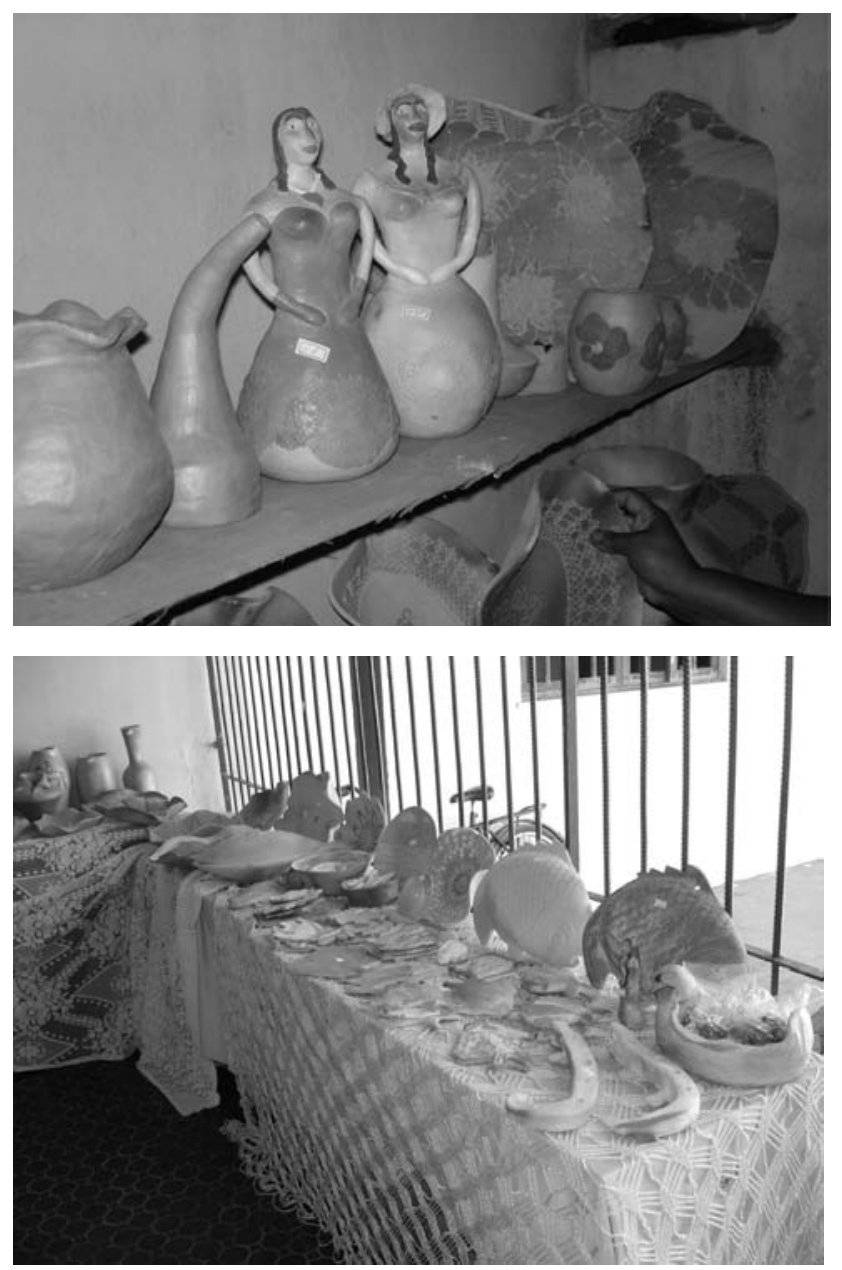

Figura 6: Peças cerâmicas produzidas pelas artesãs. [Figure 6: Ceramic pieces produced by the artisans.]

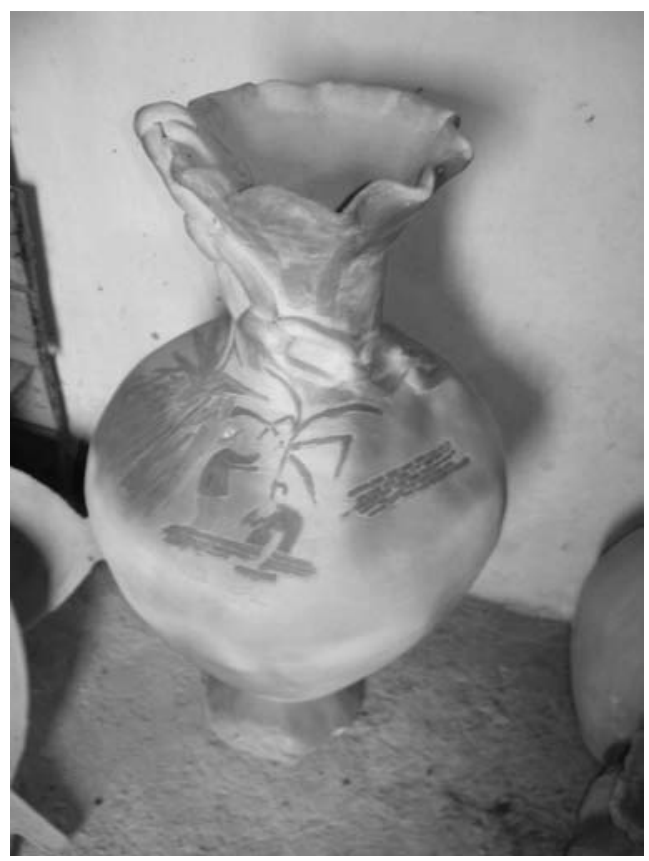

Figura 7: Peça produzida com fração de solo fino. [Figure 7: Piece produced with fine soil fraction.] 


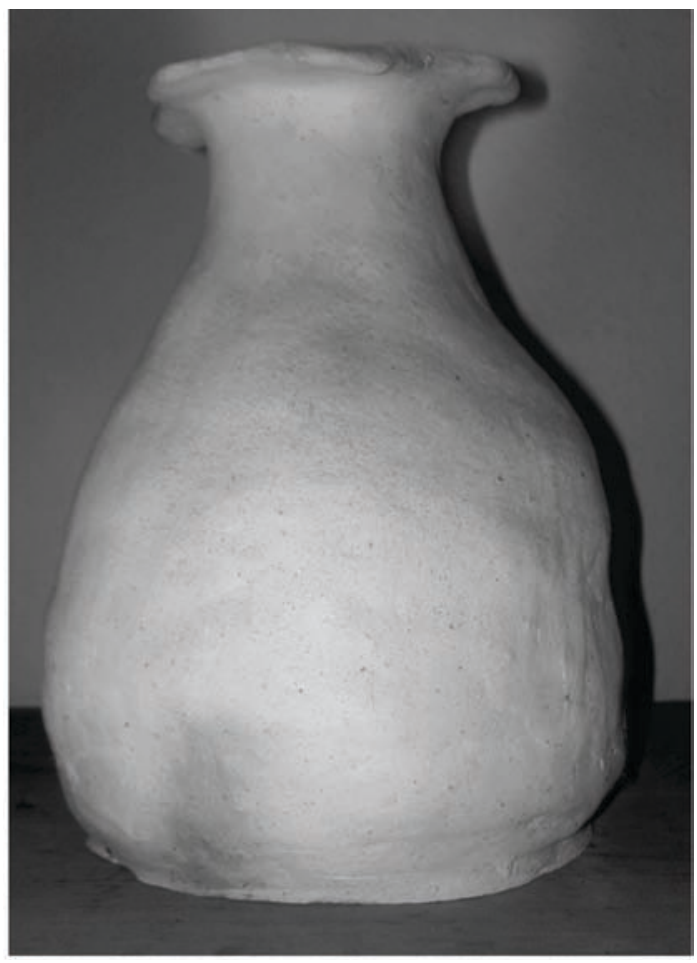

Figura 8: Peça com ranhuras, ondulações e grãos de areia resultados de uma fração de solo mais grosseira.

[Figure 8: Piece with grooves, undulations and grains of the sand resulted of a ruder soil fraction.]
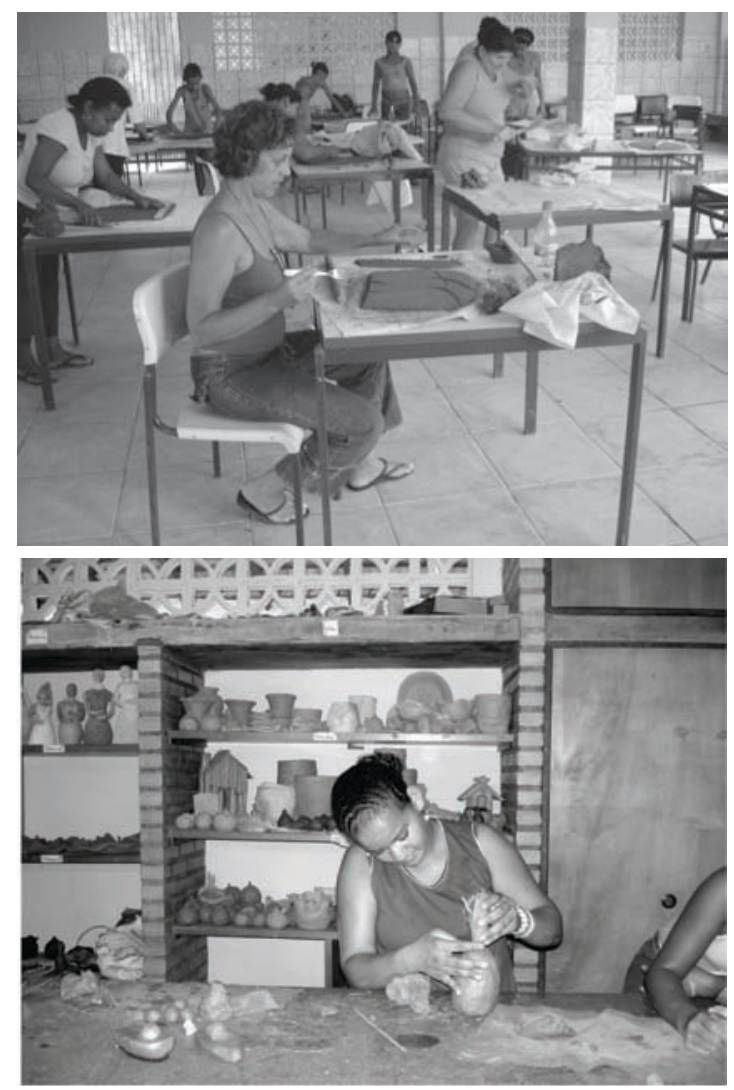

Figura 9: Artesãs modelando peças cerâmicas na localidade de São Sebastião.

[Figure 9: Artisans modeling ceramic pieces in São Sebastião.]
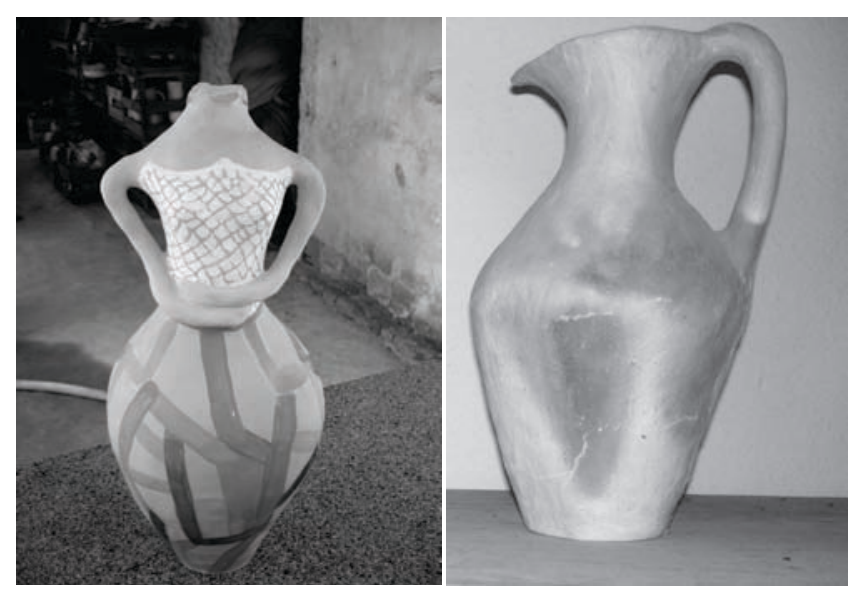

Figura 10: Peças cerâmicas estouradas após a queima e com rachaduras.

[Figure 10: Ceramic pieces burst after burning and with cracks.]

sendo necessário raspá-las e levando a ondulações mais acentuadas. Este é um fator que introduz uma dificuldade adicional para se fazer o polimento (Fig. 8).

No caso da modelagem (Fig. 9) das peças grandes, o problema continua a ocorrer, pois as artesãs elaboram paredes muito espessas, o que propicia o aparecimento de bolhas, fator determinante para o estouro dentro do forno (Fig. 10) $\mathrm{e}$, eventualmente, para o aparecimento de rachaduras que, de modo geral, não são causadas pela queima propriamente dita, visto que as mesmas são realizadas nas olarias, durante a lenta queima de seus tijolos.

\section{CONCLUSÕES}

A mesma análise técnica utilizada para caracterização e adequação dos produtos industrializados pelas industrias cerâmicas mostrou-se também adequada para o artesanato.

A matéria prima estudada, em principio, apresentou as qualidades necessárias ao trabalho artesanal como pode ser observado pelos produtos obtidos levando a um menor grau de perda.

Porém a criação de um padrão mais adequado de matéria prima a ser utilizado na arte cerâmica da baixada campista demandará, portanto, mais tempo, recursos e estudo, pois as propriedades desejadas de cada artefato tais como: cor, permeabilidade e acabamento podem estar associados a pequenas variações físicas e mineralógicas.

\section{REFERÊNCIAS}

[1] IBGE, disponível em: http://www.ibge.gov.br; acesso em 01/07/06, Instituto Brasileiro de Geografia e Estatística (2006).

[2] L. Martin, K. Suguio, J. M. Flexor, J. M. L. Dominguez, Geologia do Quaternário Costeiro do Litoral Norte do Estado do Rio de Janeiro e Espírito Santos, co-edição CPRM e FAPESP, Belo Horizonte, MG (1997) 112 p.

[3] Associação Brasileira de Normas Técnicas NBR 7181, 
Determinação da Análise Granulométrica dos Solos, Rio de Janeiro (1984) 3p.

[4] Associação Brasileira de Normas Técnicas NBR 6471, Determinação da Massa Específica, Rio de Janeiro (1984) 3p. [5] Associação Brasileira de Normas Técnicas NBR 7180, Determinação do Limite de Plasticidade, Rio de Janeiro (1984) 3p.

[6] Associação Brasileira de Normas Técnicas NBR 6459,
Determinação do Limite de Liquidez, Rio de Janeiro (1984) 3p. [7] P. S. Santos, Ciência e Tecnologia das Argilas, $2^{\text {a }}$ Ed., S. Paulo, Edgard Blucher Ltda. (1989) 499p.

[8] J. Alexandre, “Caracterização das argilas do município de Campos dos Goytacazes para utilização em cerâmica vermelha", Diss. Mestrado, Universidade Estadual do Norte Fluminense Darcy Ribeiro, Campos dos Goytacazes, RJ (1997) 170p.

(Rec. 30/08/2007, Ac. 27/12/2007) 